\title{
GRUPO DE DROGAS ILÍCITAS NO CENTRO DE ATENÇÃO PSICOSSOCIAL ÁLCOOL E OUTRAS DROGAS: OS SENTIDOS ATRIBUÍDOS AO ACOLHIMENTO. Everthon Fraga de Oliveira ${ }^{1}$ Carina Pimentel Souza Batista ${ }^{2}$; Sinara Lima de
}

\author{
Souza $^{3}$; Camila Cerqueira Rios ${ }^{4}$ e Jaciele de Souza dos Santos ${ }^{5}$
}

\author{
1. Bolsista PROBIC, Graduando em Enfermagem, Universidade Estadual de Feira de Santana, e-mail: \\ everthonfraga@hotmail.com \\ 2. Orientadora, Departamento de Saúde, Universidade Estadual de Feira de Santana, e-mail: \\ carinapimentel@hotmail.com \\ 3. Participante do projeto Percepção do acolhimento pelos usuários de um CAPS ad do interior da Bahia, Departamento de Saúde, \\ Universidade Estadual de Feira de Santana, e-mail: \\ sinarals@uefs.br \\ 4. Participante do projeto Percepção do acolhimento pelos usuários de um CAPS ad do interior da Bahia, Departamento de Saúde, \\ Universidade Estadual de Feira de Santana, e-mail: \\ mila.c.r@hotmmail.com \\ 5. Voluntária no projeto Percepção do acolhimento pelos usuários de um CAPS ad do interior da Bahia, Departamento de \\ Saúde, Graduanda em Enfermagem, Universidade Estadual de Feira de Santana, e-mail: \\ jacisdossantos@gmail.com
}

PALAVRAS-CHAVE: Saúde Mental; acolhimento; drogas ilícitas.

\section{INTRODUÇÃO}

O cenário atual da Política de Atenção à Saúde Mental Brasileira surge da luta da população e profissionais nos anos 70 na perspectiva da desinstitucionalização e extinção dos manicômios, visando acabar com a privação de liberdade (BRASIL, 2013). Buscaram-se soluções voltadas às necessidades das pessoas de forma humanizada, sobretudo para os pacientes com transtornos mentais e usuários de substâncias psicoativas assegurando - lhes seus direitos e livrando-os da situação de rua e do confinamento em manicômios, através da assistência dos Centros de Atenção Psicossocial (CAPS) (PITTA, 2011).

O serviço do CAPS propõe acolhimento; escuta; receptividade; confiança; e vínculo, além da proposta do projeto terapêutico singular (PTS) (BRASIL, 2004). Os usuários que buscam o CAPS ad, são aqueles estão em situação de sofrimento psíquico, fragilizados emocionalmente devido à dependência de substâncias psicoativas sem que haja condições de cessar o uso por conta própria (SILVEIRA, 2013). Dessa forma, a equipe do CAPS recebe, acolhe assumindo o papel de promover assistência resolutiva, responsável, tendo esse acolhimento como estratégia que orienta as práticas aproximando o indivíduo a este serviço do CAPS (PNH, 2010).

Portanto, é importante conhecer mais a respeito sobre o acolhimento, para identificar fatores que dificultam e facilitam o tratamento no CAPS, ou fatores que venham repercutir na assistência prestada por esses profissionais. Dessa forma, foi achada relevante uma abordagem desse serviço, no que diz respeito ao acolhimento a fim compreender os sentidos atribuídos pelos usuários que freqüentam o CAPS ad.

\section{METODOLOGIA}

Trata-se de uma pesquisa qualitativa, exploratória e descritiva, pois buscou-se uma abordagem do fenômeno pelo levantamento de informações que levaram o pesquisador a conhecer mais a seu respeito (TRIVIÑOS, 2008; GIL, 2010). A coleta de dados foi realizada no Centro de Atenção Psicossocial para usuários de álcool e outras drogas (CAPS ad) do município de Feira de Santana-Ba. Participou do estudo, usuários do Grupo Ajuda Mútua Droga, destinado a indivíduos que fazem uso de substâncias psicoativas. Como critério de inclusão: usuários vinculados ao grupo; que frequentavam regularmente; maiores de 18 anos; sem o efeito do uso de substâncias psicoativas no momento da coleta; condições mentais devidas sem torpor, fuga de ideias e confusão mental. Os critérios de exclusão foram estabelecidos para aqueles que não estavam aptos aos critérios de inclusão. A técnica de coleta de dados foi o Grupo Focal que consiste numa entrevista realizada em grupo que possibilita a discussão de pontos de vista e processos emocionais, a partir de uma determinada temática (GATTI, 2005). Caracteriza-se por ser uma 
técnica de pesquisa qualitativa que a partir de uma temática abordada, busca promover uma discussão entre os participantes sendo capaz de gerar através da interação social maior diversidade e riqueza nas respostas (GASKELL, 2002 apud LEITE ET AL, 2010). Os aspectos éticos foram adotados segundo a Resolução 466/2012 que regulamenta pesquisas envolvendo seres humanos (BRASIL, 2012). Trata-se de um recorte da pesquisa Percepção do acolhimento pelos usuários de um CAPS ad do interior da Bahia, aprovada no Comitê de Ética em Pesquisa (CEP - UEFS) com CAAE: 31689414.3.0000.0053 e com Resolução CONSEPE nº 090/2015.

\section{RESULTADOS E/OU DISCUSSÃO}

Os resultados obtidos foram através do grupo Ajuda Mútua Droga, denominado grupo D, que funciona desde 2005, quando também o CAPS ad foi implantado no município. O grupo é formado por homens com faixa etária de 26 a 49 anos, tendo em média 20 a 30 participantes por grupo. O presente estudo possibilitou trabalhar com três categorias de análise, por meio do grupo focal, tais como, a percepção de acolhimento; a satisfação com o atendimento e melhoria no atendimento:

\section{Atenção dos Profissionais}

A equipe multidisciplinar faz o acolhimento, essa atenção deve ser voltada totalmente ao indivíduo, sem julgamentos e valores, sendo indispensável a escuta, o vínculo e o companheirismo. Assim, é perceptível essa atenção conforme os relatos dos usuários:

''É bom, é a segundo vez que eu tô aqui, as pessoas me tratam bem, me tratam com amor, com carinho.",

'O médico é mais retraido, é tudo de boa ai. A enfermeira também é gente boa. Até o rapaz lá, do portão lá, é gente boa. A moça que fica varrendo também é gente boa.",

Nasi e Schneider (2011) trazem resultados semelhantes de usuários que percebem a atenção dos profissionais do CAPS como importante, sendo as relações desenvolvidas entre estes profissionais e usuário essencial no processo de tratamento. Contudo, outros estudos mostram resultados divergentes em que usuários notam que há deficiência na atenção por alguns profissionais que compõem a equipe multidisciplinar do CAPS (SCHNEIDER et al, 2009).

Nesta perspectiva, os usuários reiteram tal concepção aliada á ausência do estigma pelos profissionais da instituição, percebendo o serviço como local que não existe preconceito, sendo um espaço de igualdade e respeito. Essa lógica é apreendida conforme os relatos abaixo:

"Aqui tem os profissionais, eles são profissionais com bastante educação, que não tem preconceito com a gente, trata a gente de igual pra igual, mesmo a gente sendo dependente químico [..] há amor, um bom tratamento aqui, dos profissionais aqui do CAPS."

Segundo Melo e Marciel (2016) o uso da droga e o próprio usuário são notados pela sociedade como sujeitos pertencentes a um grupo específico, sendo estigmatizados e negligenciados, passando a serem vistos como sem serventia no meio social, por usarem droga. Lima (2015) reitera em seu estudo, que embora esses usuários passem por diversas perdas, o CAPS é espaço de construção de vínculo e confiança entre usuários e profissionais ocorrendo a promoção a saúde, permitindo que este sujeito seja participante ativo no seu processo de reinserção social.

\section{Vínculo com profissionais:}

Receber e manter o paciente que enfrenta problema decorrente do uso de substâncias psicoativas requer dos profissionais preparo em seu exercício profissional, ou seja, um atendimento sensível, responsável, de respeito, sobretudo humanizado. Essas ações favorecem a confiança e o vínculo dos usuários que lhes são atribuídos sentimentos conforme os relatos:

'"...]Tem um ótimo atendimento, tem profissionais que me entendem. E também as outras pessoas do grupo, são umas pessoas legais.

'"...] Quando eu to jogando futebol me sinto feliz. E quando eu to aqui no CAPS com vocês (profissionais). E com meus colegas",

Nasi e Scheneider (2011) trazem a percepção e a satisfação dos usuários que falam sobre a representatividade dos trabalhadores do CAPS atrelado ao tratamento, ressaltando que através da relação e do vínculo, estes sujeitos são essenciais no processo terapêutico. A construção do 
vínculo na saúde mental depende da forma com que esse profissional se envolve no tratamento do paciente atendendo as necessidades deste usuário trazendo resolubilidade as suas demandas (JORGE et al, 2011). Pereira e Palma (2017) mostram resultados que convergem no que tange ao vínculo desenvolvido entre esses profissionais e usuários, no CAPS os usuários notam as oficinas terapêuticas como momento de socialização, sendo possível a troca de experiências, atribuindo sentimento de pertencimento por sentirem livres para se expressarem.

\section{Vinculo com outros usuários:}

O CAPS também é espaço para o vínculo com outras pessoas do mesmo grupo de ajuda. Essa relação desenvolvida devido à convivência entre esses sujeitos atribuem sentimentos de confiança, respeito, amizade, e felicidade em pertencer ao grupo conforme os relatos:

''Aqui no CAPS eu me sinto bem, é um lugar que eu me sinto bem. Quando eu tô aqui eu tô alegre também, quando eu tô com meus colegas qui e com vocês"'

'Galera boa. Ninguém prejudica ninguém. Ninguém tem preconceito com ninguém. E assim a gente vai vivendo.

Dalpiaz (2014) mostra que o CAPS tem um importante papel no que diz respeito ao resgate da autonomia, confiança, e que através desse ambiente o convívio com os grupos possibilita que esses usuários troquem experiências entre si, e que a oficina terapêutica é uma forma de fortalecimento do vínculo entre estes sujeitos. Moura (2011) reitera mediante a percepção de usuários relacionados ao vínculo desenvolvido que essas oficinas terapêuticas possibilitam novas experiências entre eles, sendo possível se ajudarem, compartilharem sobre melhoras e recaídas. Sob essa lógica de convívio e confiança, esses usuários expandem o olhar para o tratamento na perspectiva de que o Caps seja um espaço atrativo.

\section{Acompanhamento da Família}

É imprescindível o acompanhamento da família pelos profissionais do CAPS no sentido de apoio familiar, embora foi notado essa ausência da equipe do Caps conforme a fala do usuário:

'’..] Os profissionais pra família, chegar pra família, ligar pra família. Porque, a minha família ela não é preparada, né. Então o CAPS, ela pode ajudar minha família né, a poder me ajudar dentro de casa. Porque a gente ta sendo ajudado aqui. E lá dentro de casa?! Né? E lá dentro? Como é que fica? Porque não adianta a gente ser ajudado aqui e lá dentro, dentro da nossa casa, é, a nossa mãe não ter como nos ajudar né. Então é isso."

A visita domiciliar feita pela equipe da saúde da família juntamente com a equipe do CAPS direciona o processo de trabalho desses profissionais facilitando na compreensão do profissional sobre a dinâmica familiar e como esse usuário está inserido nela, além de proporcionar o vínculo entre os sujeitos (PINHO et al, 2015).

Zanatta (2012) traz que a problemática das recaídas pelo uso de drogas durante o tratamento ocorre devido a conflitos ocasionados em âmbito familiar, dificultando o processo de tratamento.

Um estudo realizado em um CAPS de Porto Alegre mostra que familiares de usuários não possuía esse acompanhamento domiciliar, e até mesmo desconheciam essa prática, sendo inviabilizada devido às condições não favoráveis para o serviço ou a não priorização dessa atividade pelos profissionais do CAPS (CAMATTA, 2010).

\section{CONSIDERAÇÕES FINAIS}

Para que essa assistência do CAPS seja eficaz, requer da equipe multidisciplinar preparo, a exemplo de educação continuada. O vínculo neste estudo é atribuído pelos usuários como melhor forma para o enfrentamento da terapêutica e as dificuldades durante a permanência no CAPS, onde é relatada a interação com os profissionais e outras pessoas (usuários) havendo o compartilhamento das experiências, assim como a promoção do exercício da sua participação ativa no CAPS. O vínculo também é uma importante estratégia para manter usuários e famílias conectados ao serviço, e sob essa lógica, é imprescindível o apoio da equipe do CAPS ad juntamente com a equipe de Saúde da Família. Porém, é evidente neste estudo uma fragilidade por parte dos profissionais no acompanhamento da família. O CAPS deve adotar estratégias para promover essa interlocução, através de visitas, ligações, bem como promover atividades que 
possibilite um melhor acompanhamento dessa família no CAPS, na perspectiva de assegurar apoio psicológico para o melhor manejo com o usuário de substância psicoativo âmbito residencial.

\section{REFERÊNCIAS}

BAUER, M. W; GASKELL, G. Pesquisa Qualitativa com Texto, Imagem e Som: um manual prático. Editora Vozes, Petrópolis, RJ. 2002.

BRASIL, Ministério da Saúde. Secretaria de Atenção à Saúde. Cadernos de Atenção Básica. Saúde mental. Departamento de Ações Programáticas Estratégicas. - Brasília: Ministério da Saúde, 2013.

BRASIL. Ministério da Saúde. Cartilha do PNH. Acolhimento nas Práticas de Produção em Saúde. Brasília, DF. 2010.

BRASIL. Ministério da Saúde. Resolução no 466 de 12 de dezembro de 2012 do Conselho Nacional de Saúde. Brasília, DF: Ministério da Saúde, 2012.

BRASIL. Ministério da Saúde. Secretaria de Atenção à Saúde. Departamento de Ações Programáticas Estratégicas. Saúde mental no SUS: os centros de atenção psicossocial. Brasília, 2004.

CAMATTA, Marcio Wagner et al. Avaliação de um centro de atenção psicossocial: o olhar da família. Ciênc. saúde coletiva, Rio de Janeiro, v. 16, n. 11, p. 4405-4414, Nov. 2011.

DALPIAZ, A.K et al. Fatores associados ao uso de drogas: depoimentos de usuários de um Caps Ad. Aletheia. no.45 Canoas dez. 2014

GATTI, B. A. Grupo focal nas pesquisas em ciências sociais e humanas. Brasília: Liber Livro,2005.

GIL, A. C. Como elaborar projetos de pesquisa. 5 ed. São Paulo: Atlas, 2010. 184 p.

JORGE, M.S.B et al. Promoção da Saúde Mental- Tecnologia do cuidado: vínculo, acolhimento, co-responsabilização e autonomia. Ciência \& Saúde Coletiva. Fortaleza, CE. 2011.

LIMA, MZ et al.Percepção do cuidado em saúde no CAPSad: uma visão do paciente. Saúde (Santa Maria), Vol. 41, n. 1. Fortaleza, CE. Jan, 2015.

MELO, J.R. F; MACIEL, S. C. Representação Social do Usuário de Drogas na Perspectiva de Dependentes Químicos. Psicol. cienc. Prof., Brasília , v. 36, n. 1, p. 76-87, Mar. 2016. MOURA, F.G; SANTOS, J.E. O cuidado aos usuários de um centro de atenção psicossocial álcool e drogas: Uma visão do sujeito coletivo. SMAD, Rev. Eletrônica Saúde Mental Álcool Drog. (Ed. port.) Salvador-ba. Set.-dez. 2011.

NASI, C; SCHNEIDER, J.F.O Centro de Atenção Psicossocial no cotidiano dos seus usuários.

Rev Esc Enferm USP. 45(5): 1157-63. Rio Grande do Sul, 2011.

PEREIRA, Ondina Pena; PALMA, Ana Carolina Ribas. Sentidos das oficinas terapêuticas ocupacionais do CAPS no cotidiano dos usuários: uma descrição fenomenológica. Rev.

abordagem gestalt., Goiânia, v. 24, n. 1, p. 15-23, abr. 2018.

PINHO, Eurides Santos; SOUZA, Adrielle Cristina Silva; ESPERIDIAO, Elizabeth. Processos de trabalho dos profissionais dos Centros de Atenção Psicossocial: revisão integrativa. Ciênc. saúde coletiva, Rio de Janeiro, v. 23, n. 1, p. 141-152, Jan. 2018.

PITTA, Ana Maria Fernandes. Um balanço da reforma psiquiátrica brasileira: instituições, atores e políticas. Ciênc. saúde coletiva, Rio de Janeiro, v. 16, n. 12, p. 4579-4589, Dez. 2011. SCHNEIDER, J. F. et al. Avaliação de um Centro de Atenção Psicossocial Brasileiro. Ciencia y EnfermerIa XV (3): 91-100, 2009.

SILVEIRA, E.R. Clínica da Toxicomania: Recortes de uma Experiência em Caps Ad. Revista Mal-estar e Subjetividade.Vol. XIII - No 3-4 - p. 665 - 686. Fortaleza, 2013.

SILVEIRA, ER. Clínica da Toxicomania: Recortes de uma Experiência em Caps Ad. Revista Mal-estar e Subjetividade.Vol. XIII - No 3-4 - p. 665 - 686. Fortaleza, 2013.

TRIVINÕS, A. N. S. Introdução à pesquisa em ciências sociais: a pesquisa qualitativa em educação: o positivismo, a fenomenologia, o marxismo. São Paulo: Atlas, 2008. 175 p. ZANATTA, A.B. et al. O centro de atenção psicossocial álcool e drogas sob a percepção do usuário. Revista Baiana de Saúde Pública. v.36, n.1, p.225-237 